\title{
Palliation of Neoplastic Esophageal Strictures with Metallic Stents
}

\author{
Neda Nozari \\ Department of Gastroenterology, Yas Hospital, Tehran University of Medical Sciences, Tehran, Iran \\ Email address: \\ nozari_neda@yahoo.com \\ To cite this article: \\ Neda Nozari. Palliation of Neoplastic Esophageal Strictures with Metallic Stents. Journal of Cancer Treatment and Research. \\ Vol. 5, No. 6, 2017, pp. 86-89. doi: 10.11648/j.jctr.20170506.11
}

Received: September 18, 2017; Accepted: September 28, 2017; Published: November 6, 2017

\begin{abstract}
Most patients with advanced esophageal neoplasm have dysphagia and suffer from cachexia and malnourishment. Supportive treatments focus on symptom palliation and improving quality of life at this time. Guidelines illustrated some indications for stent use in esophageal neoplasm such as inoperable neoplastic obstruction, presence of neoplastic fistula or perforation, tumor recurrence and contraindication for chemo-radiotherapy. Palliative stents help relieve dysphagia, manage mouth secretions, reduce aspiration risk, and maintain oral intake. Stent placement sometimes requires both endoscopic and fluoroscopic guidance. A stricture dilation is not necessary before stent placement. Success rate of SEMS placement was reported $80-100 \%$. Complications of stents are bleeding, perforation, migration, and tumor ingrowth. Coated SEMS are the treatment of choice in the presence of neoplastic trachea-esophageal fistula. Partially covered stents are used for neoplastic stricture but their removal is sometimes difficult. The stent can be left in esophagus indefinitely for palliation in cases with progressive disease. In this article, we reviewed the recent literatures for efficacy of palliative metal stents placement in patients with esophageal neoplasm.
\end{abstract}

Keywords: Dysphagia, Esophageal Cancer, Esophageal Stent, Self Expandable Metal Stent

\section{Introduction}

The prevalence of gastrointestinal neoplasms including esophageal neoplasm continues to increase in the world [1, 2]. The most of patients with esophageal neoplasm are diagnose at an advanced and incurable stage. Patients need to palliative treatment at this time of diagnosis [1-4]. 5 year Survival of esophageal neoplasm is 5-15\% [2, 4-6]. Palliative treatments like stents can be offered as the first choice at this stage [1-2, 6-12]. Because most of patients suffer from dysphagia due to balk of tumor lesion and unfortunately are un-resectable at the diagnosis time [1-2]. Endoscopic placement of stents has been shown to rapid dysphagia relief [1, 3, 13-14]. Maintenance of oral intake, nutritional support, manage mouth secretions, and reduce aspiration risk are essential for these patients [12-13]. Guidelines illustrated some indications for stent use in esophageal neoplasm including inoperable neoplastic obstruction, presence of neoplastic fistula or leakage or perforation, tumor recurrence and contraindication for chemo-radiotherapy [10, 15-16]. Contraindication of stents placement are curable neoplasm, uncorrectable coagulopathy, presence neoplasm within $2 \mathrm{~cm}$ of upper esophageal sphincter, within 6 weeks of chemoradiotherapy, ill patients, gastrointestinal obstruction, airway compression risk and sepsis [15-16]. The aim of this review article was to highlight safety and efficacy of palliative metal stents placement in patients with advanced esophageal neoplasm.

\section{Stent Selection}

Endoscopic endoprothesis has been introduced as an easy, rapid and less complication technique for palliation of neoplastic dysphagia compared with palliative surgery [17]. A good esophageal endoprothesis has easy to use delivery system and ability to reposition. Different types of stents are available including plastic stent and metal stent. A major complication of plastic stent was immigration and weren't very useful and effective for patients with esophageal neoplasm [17-18]. Self-expanding metallic stents [SEMS] had fewer complications compared to plastic stents $[10,17]$. SEMS are partially covered or fully covered. Table 1 has 
showed the characteristics of each SEMS briefly $[15,17]$.

Table 1. Characteristics of Self-expanding Metallic Stents [15, 17].

\begin{tabular}{llllll}
\hline \multirow{2}{*}{ Material } & Ultraflex & Wallstnet I & Wallstent II & Z-stent & Choo stent \\
\cline { 2 - 6 } & Nitinol & Elgiloy & Elgiloy & Stainless steel & Stainless steel \\
\hline Delivery system diameter (F) & 24 & 38 & 18 & 28 & 25 \\
Covering & Yes & Yes & Yes & Yes & Yes \\
Design & Mesh & Mesh & Mesh & Zigzag & Zigzag \\
Radial force & + & ++++ & +++ & ++ & ++ \\
Liuminal diameter (mm) & 16,18 & 18 & 19 & 18 & 18,21 \\
Closure of fistula & Yes & Yes & Yes & Yes & Yes \\
Degree of shortening (\%) & $30-40$ & 20 & 30 & $0-10$ & 0 \\
\hline
\end{tabular}

Ultraflex stent (Boston Scientific), Wallstent (Boston Scientific, Natick, MA), Gianturco-Rosch-Z stent (Cook Europe), Choo stent (Solco Intermed, Seoul, South Korea).

\section{Technique of Insertion}

Location of tumor was seen in mid part of esophagus in more than half of patients $[8,19-20]$. SEMS is preferred for mid esophageal neoplasm but also can be used in each part of esophagus just considered at least $2 \mathrm{~cm}$ away from upper esophageal sphincter $[10,15]$. SEMS should be placed at least after 6 weeks of the completion of chemo-radiotherapy for the prevention of the chest pain complication [15-16, 21]. Some studies advised one barium esophagogram to define clearly narrowing of neoplastic lesion and presence of treacheo-esophageal fistula if there was any clinical suspicious by upper endoscopy [10, 17]. Stent selection should be basis on tumor location, operator experience and expected survival $[10,15,17]$. Stent placement sometimes requires both endoscopic and fluoroscopic guidance [22]. The SEMS should be placed $2 \mathrm{~cm}$ above and below the neoplastic lesion and dilatation is not necessary. Neoplastic lesion in proximal part of esophagus is difficult for using SEMS procedure and success rate is lower than distal part $[10,15,17]$. Some studies recommended $7 \mathrm{~mm}$ length and $18 \mathrm{~mm}$ diameter of SEMS in cervical esophagus according to reduced complications such as foreign body sensation [17]. The use of partially or fully covered metal stents in subjects with neoplasm fistula or perforation were useful and with good results [2, 17, 23-24]. Modified covered SEMS prevents from stent migration [23]. Success rate of SEMS placement was reported $80-100 \%[1,19,25-26]$. Table 2 summarized results of some studies for using SEMS in advanced esophageal neoplasm.

Table 2. Results of Some Studies According to Using SEMS in Advanced Esophageal Neoplasm.

\begin{tabular}{|c|c|c|c|c|c|c|}
\hline & Singh, et al 20 & Khamaysi, et al 1 & Gray, et al 27 & Shim, et al 23 & Park, et al 25 & Johnson, et al 28 \\
\hline Patients number & 100 & 42 & 53 & 61 & 32 & 92 \\
\hline Proximal tumor & $5 \%$ & $4.8 \%$ & NR & $3.3 \%$ & $12.5 \%$ & $71.8 \%$ \\
\hline Distal tumor & $37 \%$ & $78.5 \%$ & NR & $37.7 \%$ & $65.6 \%$ & $28.2 \%$ \\
\hline Re-stenting & $6 \%$ & $30.9 \%$ & $22.6 \%$ & NR & $21.9 \%$ & $14 \%$ \\
\hline $\begin{array}{l}\text { Median survival } \\
\text { NR. Not reported }\end{array}$ & $<22$ weeks & 17 weeks & $>4$ weeks & NR & $<14$ weeks & 16 weeks \\
\hline
\end{tabular}

\section{Post Procedure Complications}

Immediate complications of SEMs such as perforation or bleeding of esophagus are rare [11, 19, 29]. Early and late complications following the SEMS placement summarized in table 3 and reported between $11.5-43.4 \%$ in some studies $[1,23,27]$.

Table 3. Results of Some Studies About Complications of SEMS.

\begin{tabular}{lllllll}
\hline & Zaidi, et al 2 & Shim, et al 23 & Christie, at al 30 & Uitdehaag, et al 3 & Tian, et al 8 & Uesato, et al 21 \\
\hline Chest pain & $10 \%$ & $5 \%$ & $\mathrm{NR}$ & $16 \%$ & $17.6 \%$ & \\
GERD & $20 \%$ & $5 \%$ & $\mathrm{NR}$ & $13 \%$ & $\mathrm{NR}$ \\
Tumor ingrowth & $20 \%$ & $0 \%$ & $33 \%$ & $\mathrm{NR}$ & $\mathrm{NR}$ \\
Stent migration & $10 \%$ & $0 \%$ & $8.7 \%$ & $13.7 \%$ & $\mathrm{NR}$ & $5.5 \%$ \\
\hline
\end{tabular}

GERD. Gastroesophageal reflux, NR. Not reported.

Tumor ingrowth can be decreased by using of covered SEMS, but with an increased rate of stent migration $[10,15]$. The migration risk increase when the stent is placed across the gastroesophageal junction [22]. Partially covered SEMS help to prevent migration but their removal is sometimes difficult according to high rate of tumor in growth $[18,31]$.

\section{Survival After Insertion of SEMS}

Median survival rate of unresectable esophageal neoplasm is 3-6 months [14, 26]. Mean survival times after SEMS was 90-150 days in some studies. Patients sometimes survived 
more than one year also [14, 20, 26, 28, 32]. The stent can be left in esophagus indefinitely for palliation in cases with progressive disease [4]. The median survival of patients with SEMS and re-stenting sometimes was significantly longer (222 \pm 26 days) than patients with SEMS and without reintervention [29]. Survival is not related to the location of neoplasm in the esophagus or its histologic type after SEMS insertion [26].

\section{Conclusion}

More than $50 \%$ of esophageal neoplasm in advanced stage needs to palliative treatments for dysphagia. Endoscopically placed esophageal stents help fast relieve of their dysphagia and offer a good quality of life. SEMS are safe and effective with relatively few complications. Late complications such as stent migration or tumor in growth are treated by reintervention of endoscopy in most of time. Coated SEMS are the treatment of choice in patients with neoplastic dysphagia in the presence of trachea-esophageal fistula. Although partially covered stents are designed for esophageal neoplasm but their removal is sometimes difficult. The stent can be left in esophagus indefinitely for palliation in cases with progressive disease.

\section{References}

[1] Khamaysi I, Andraous M, Suissa A, Yassin K. Selfexpandable metallic stents for the palliation of malignant dysphagia: a single center experience. Cancer Research Frontiers. Vol.3, No.2, 2016, pp.277-85.

[2] Zaidi NH, Sibiani A. Palliation of Malignant Esophageal Obstruction and Fistulas with Metallic Stents: A Tertiary Center Experience. Surgical Science. Vol.12, No.7, 2016, pp.199.

[3] Sgourakis G, Gockel I, Radtke A, Dedemadi G, Goumas K, Mylona S, Lang H, Tsiamis A, Karaliotas C. The use of selfexpanding stents in esophageal and gastroesophageal junction cancer palliation: a meta-analysis and meta-regression analysis of outcomes. Digestive diseases and sciences. Vol.3, No.55, 2016, pp.3018-30.

[4] Paeschke A, Bojarski C, Küpferling S, Hucklenbroich T, Siegmund B, Daum S. Unintentional Long-Term Esophageal Stenting due to a Complete Response in a Patient with Stage UICC IV Adenocarcinoma of the Gastroesophageal Junction. Case reports in gastroenterology. Vol.10, No.2, 2016, pp.21823.

[5] Sundelöf M, Ye W, Dickman PW, Lagergren J. Improved survival in both histologic types of oesophageal cancer in Sweden. International journal of cancer. Vol.10, No.99, 2002, pp.751-4.

[6] Pennathur A, Chang AC, McGrath KM, Steiner G, AlveloRivera M, Awais O, Gooding WE, Christie NA, Gilbert S, Landreneau RJ, Luketich JD. Polyflex expandable stents in the treatment of esophageal disease: initial experience. The Annals of thoracic surgery. Vol.30, No.85, 2008, pp.1968-73.

[7] Sihvo EI, Luostarinen ME, Salo JA. Fate of patients with adenocarcinoma of the esophagus and the esophagogastric junction: a population-based analysis. The American journal of gastroenterology. Vol.1, No.99, 2004, pp.419.

[8] Tian D, Wen H, Fu M. Comparative study of self-expanding metal stent and intraluminal radioactive stent for inoperable esophageal squamous cell carcinoma. World journal of surgical oncology. Vol.22, No.14, 2016, pp.18.

[9] Radecke K, Gerken G, Treichel U. Impact of a self-expanding, plastic esophageal stent on various esophageal stenoses, fistulas, and leakages: a single-center experience in 39 patients. Gastrointestinal endoscopy. Vol.30, No.61, 2005, pp.812-8.

[10] Ramakrishnaiah VP, Malage S, Sreenath GS, Kotlapati S, Cyriac S. Palliation of Dysphagia in Carcinoma Esophagus. Clinical medicine insights. Gastroenterology. Vol.9, No.11, 2016.

[11] Dormann AJ, Eisendrath P, Wigginghaus B, Huchzermeyer H, Devière J. Palliation of esophageal carcinoma with a new selfexpanding plastic stent. Endoscopy. No.35, 2003, pp.207-11.

[12] Philips P, North DA, Scoggins C, Schlegel M, Martin RC. Gastric-esophageal stenting for malignant dysphagia: results of prospective clinical trial evaluation of long-term gastroesophageal reflux and quality of life-related symptoms. Journal of the American College of Surgeons. Vol.31, No.221, 2015, pp.165-73.

[13] Mariette C, Gronnier C, Duhamel A, Mabrut JY, Bail JP, Carrere N, Lefevre JH, Meunier B, Collet D, Piessen G, FREGAT Working Group-FRENCH. Self-expanding covered metallic stent as a bridge to surgery in esophageal cancer: impact on oncologic outcomes. Journal of the American College of Surgeons. Vol.31, No.220, 2015, pp.287-96.

[14] Selinger CP, Ellul P, Smith PA, Cole NC. Oesophageal stent insertion for palliation of dysphagia in a District General Hospital: experience from a case series of 137 patients. QJM: An International Journal of Medicine. Vol.27, No.101, 2008, pp.545-8.

[15] Katsanos K, Sabharwal T, Adam A. Stenting of the upper gastrointestinal tract: current status. Cardiovascular and interventional radiology. Vol.1, No.33, 2010, pp.690-705.

[16] Baerlocher MO, Asch MR. Interdisciplinary Canadian guidelines on the use of metal stents in the gastrointestinal tract for oncological indications. Canadian Association of Radiologists Journal. Vol.1, No.59, 2008, pp.107. [Abstract].

[17] Shim CS, Jung IS. Metal stents for palliation of inoperable carcinoma of the gastrointestinal tracts. Digestive Endoscopy. Vol.3, No.16, 2004, pp. s1.

[18] Yakoub D, Fahmy R, Athanasiou T, Alijani A, Rao C, Darzi A, Hanna GB. Evidence-based choice of esophageal stent for the palliative management of malignant dysphagia. World journal of surgery. Vol.1, No.32, 2008, pp.1996.

[19] Jain PK. Safety of endoscopic self-expanding metallic stent placement in esophageal cancer without fluoroscopy. International Surgery Journal. Vol.10, No.3, 2016, pp.1757-60.

[20] Singh P, Singh A, Singh A, Sharma G, Bhatia PK, Grover AS. Long Term Outcome in Patients with Esophageal Stenting for Cancer Esophagus-Our Experience at a Rural Hospital of Punjab, India. Journal of clinical and diagnostic research: JCDR. Vol.10, No.12, 2016, pp. PC06. 
[21] Uesato M, Akutsu Y, Murakami K, Muto Y, Kagaya A, Nakano A, Aikawa M, Tamachi T, Arasawa T, Amagai H, Muto Y. Comparison of Efficacy of Self-Expandable Metallic Stent Placement in the Unresectable Esophageal Cancer Patients. Gastroenterology Research and Practice. 2017.

[22] Mao A. Interventional therapy of esophageal cancer. Gastrointestinal tumors. Vol.3, No.2, 2016, pp.59-68.

[23] Shim CS, Cho YD, Moon JH, Kim JO, Cho JY, Kim YS, Lee JS, Lee MS. Fixation of a modified covered esophageal stent: its clinical usefulness for preventing stent migration. Endoscopy. Vol.33, No.20, 2001, pp.843-8.

[24] Balazs A, Galambos Z, Kupcsulik PK. Characteristics of esophagorespiratory fistulas resulting from esophageal cancers: a single-center study on 243 cases in a 20-year period. World journal of surgery. Vol.1, No.33, 2009, pp.9941001 .

[25] Park JG, Jung GS, Oh KS, Park SJ. Double-layered PTFEcovered nitinol stents: experience in 32 patients with malignant esophageal strictures. Cardiovascular and interventional radiology. Vol.1, No.33, 2010, pp.772-9.

[26] Burstow M, Kelly T, Panchani S, Khan IM, Meek D, Memon B, Memon MA. Outcome of palliative esophageal stenting for malignant dysphagia: a retrospective analysis. Diseases of the Esophagus. Vol.1, No.22, 2009, pp.519-25.

[27] Gray RT, O'donnell ME, Scott RD, McGuigan JA, Mainie I. Self-expanding metal stent insertion for inoperable esophageal carcinoma in Belfast: an audit of outcomes and literature review. Diseases of the Esophagus. Vol.1, No.24, 2011, pp.569-74.

[28] Johnson E, Enden T, Noreng HJ, Holck-Steen A, Gjerlaug BE, Morken T, Johannessen HO, Drolsum A. Survival and complications after insertion of self-expandable metal stents for malignant oesophageal stenosis. Scandinavian journal of gastroenterology. Vol.1, No.41, 2006, pp.252-6.

[29] Homann N, Noftz MR, Klingenberg-Noftz RD, Ludwig D. Delayed complications after placement of self-expanding stents in malignant esophageal obstruction: treatment strategies and survival rate. Digestive diseases and sciences. Vol.1, No.53, 2008, pp.334-40.

[30] Christie NA, Buenaventura PO, Fernando HC, Nguyen NT, Weigel TL, Ferson PF, Luketich JD. Results of expandable metal stents for malignant esophageal obstruction in 100 patients: short-term and long-term follow-up. The Annals of thoracic surgery. Vol.30, No.71, 2001, pp.1797-802.

[31] Uitdehaag MJ, Siersema PD, Spaander MC, Vleggaar FP, Verschuur EM, Steyerberg EW, Kuipers EJ. A new fully covered stent with antimigration properties for the palliation of malignant dysphagia: a prospective cohort study. Gastrointestinal endoscopy. Vol.31, No.71, 2010, pp.600-5.

[32] Uitdehaag MJ, van Hooft JE, Verschuur EM, Repici A, Steyerberg EW, Fockens P, Kuipers EJ, Siersema PD. A fullycovered stent (Alimaxx-E) for the palliation of malignant dysphagia: a prospective follow-up study. Gastrointestinal endoscopy. Vol.31, No.70, 2009, pp.1082-9. 